\title{
IDENTIDAD PROFESIONAL DOCENTE
}

Isabel Cantón Mayo y Maurice Tardif (Coordinadores)

Narcea S. A de Ediciones: España, 2018

Reseña realizada por

\section{Marcelo Arancibia Herrera \\ Universidad Austral de Chile marceloarancibia@uach.cl}

El libro aquí reseñado "Identidad Profesional Docente", coordinado por Isabel Cantón Mayo y Maurice Tardif, reúne estudios y reflexiones desde diversos lugares y miradas. Lo cual se constituye en un mérito pues dicha diversidad no se expresa para confundir al lector o difuminar una perspectiva sobre este tema, más bien, nos permite comprender que con dicha diversidad logramos aunar una perspectiva, reunir antecedentes, congregar posiciones, en definitiva, entender que la Identidad Docente es un aspecto relevante para atender en diferentes ámbitos y niveles educativos: políticos, gubernamentales, globales, locales, escuelas, investigación, formación, etc. Léase entonces dicha diversidad como un valor de este compendio.

Por otra parte, en un mundo convulsionado y con una profesión docente sitiada por una opresora globalización neoliberal, un libro como éste viene a recordarnos que el Docente es un humano, por tanto, un sujeto en construcción que depende de sus interrelaciones en contextos situados. El recorrido por los diferentes capítulos nos adentra en esta perspectivación del profesor como sujeto en permanente transformación, que posee una identidad movible pero que a su vez persigue transformar la realidad que le configura. Esta doble vía de querer transformar y ser transformado, sin duda lo sitúa como un ser que vive contradicciones vitales no solo en tanto profesional si no también personal.

El sujeto profesor a diferencia de otras profesiones se involucra en quehaceres íntimos con otras y otros, se hace responsable del crecimiento y construcción de otras y otros, de allí la tensión permanente hacia su identidad y por ende hacia los enfoques o paradigmas que le sitúan como un técnico, un práctico o un emancipador. 
Hoy más que nunca urge levantar la perspectiva del profesor como un profesional que es capaz de transformar sus contextos, tocar a sus estudiantes, generar momentos luminosos de aprendizaje, que sustenta su práctica en un curriculum escolar muchas veces ideado por “especialistas" que obliga a los maestros a supeditar sus idearios pedagógicos a la implementación de actividades de aula poco significativas o bien descontextualizadas. Asimismo, luego se les evalúa en función de logros estandarizados que buscan medir el cumplimiento de dicho curriculum.

Un elemento destacado en gran parte de los estudios presentados en el libro, ponen acento en que para un buen desempeño docente es sustancial tener programas de Formación Inicial (en adelante FID) altamente exigentes y de calidad. Indudablemente, los sistemas educativos con mejores resultados, comúnmente son selectivos con el acceso a la FID, entregan una formación rigurosa, centrada en conocimientos disciplinarios y didácticos, ponen énfasis en prácticas progresivas, procurando que los estudiantes desarrollen habilidades y competencias mínimas para desplegarse en el aula escolar. Asimismo, destacan en formar profesionales como prácticos reflexivos que construyan una identidad profesional que supere la visión tradicional y no reproduzca prácticas naturalizadas.

En este un mundo globalizado, en contexto de cambios, los profesores viven en una encrucijada, por un lado, una sociedad que les exige ser pilares del desarrollo pero que, por otro, no les prepara, no entrega condiciones, ni les respeta profesionalmente. En esta lógica de requerimientos, no solo deben organizar la enseñanza, sino que también, ser responsables del aprendizaje de estudiantes que cada vez menos quieren estar en la escuela, convivir con familias que cada vez menos confían en ellos y ser parte de una sociedad que les valora cada vez menos, a tal punto de generar una “destrucción” de su identidad.

Lo descrito, provoca profundas transformaciones en la identidad de profesores, pues el contexto escolar de los últimos 20 años ha sido sin duda un escenario cambiante permeado por una sociedad postmoderna y liquida (usando el concepto de S. Bauman). De allí que surge como imprescindible dotar de estabilidad al sistema siendo necesarias políticas sistémicas consensuadas, con sostenimiento en el tiempo, que contemplen la variedad de factores que intervienen en la difícil tarea de aprender y de enseñar.

En sintonía con lo anterior, la formación de profesores debe realizarse durante toda su larga 
carrera, atendiendo no solo cuestiones técnicas, si no también humanas, dado el alto deterioro de su salud y desgaste profesional. Por ejemplo, incluir en la formación continua jornadas de cómo aprender de la experiencia y cómo construir conocimiento profesional, dentro de las propias comunidades educativas. Puesto que, saber cuáles serán los contextos futuros de ejercicio profesional en las escuelas es improbable, lo que hace casi imposible preparar a los maestros para cada una de las contingencias a las que puede tener que enfrentarse en las aulas.

En el libro se vislumbra una re-conceptualización de la identidad profesional docente como un problema a nivel global, ya que según la evidencia al menos desde unos cuarenta años existe una pérdida de la identidad profesional como efecto importante producido por nuevas condiciones estructurales y sistémicas en la percepción entre los docentes de pertenencia a una profesión despreciada por la sociedad, aun cuando algunos profesores, se declaran satisfechos con su desempeño y con las relaciones en las comunidades escolares, persiste la sensación de insatisfacción respecto al bajo valor que la sociedad asigna a su labor. Con todo ello, los docentes ven disminuida su autoestima profesional y personal.

Con todo el libro transita desde experiencias nacionales como las de Canadá, Francia, Chile España y Suiza, así como por todos los niveles de la educación escolar: primaria, secundaria, universitarios, profesores principiantes y con experiencia. Lo cual revela un exhaustivo y completo panorama de la identidad profesional.

Inicia el libro con el capítulo de Tardif y Le Vasseur, quienes nos hablan de una identidad en mutación, anclada en el contexto canadiense. Sin embargo, más allá de ser una constatación y descripción de dicha realizad, los autores urgen atender la cuestión antes que "estalle" un problema mayor traducido en los múltiples "roles" que debe cumplir el maestro.

El segundo capítulo de Isabel Cantón, construye una interesante ecuación entre calidad, identidad, situaciones contextuales con indicadores de satisfacción, lo cual revela cierta imposibilidad de relacionar la identidad profesional con la calidad, por razones que van desde la polisemia conceptual hasta las diferencias contextuales que priman en los niveles de satisfacción personal respecto de los desempeños profesionales.

El capítulo de Carlos Marcelo y Carmen Gallego, ante una pregunta existencial ¿quién soy yo como maestro? invitan a generar procesos de construcción de identidad en profesores 
principiantes mediante el método de investigación reflexivo-metafórico, muestran cinco ejercicios para reflexionar y auto investigar sobre la identidad docente.

El cuarto capítulo de Pelletier y Morales-Perlaza, nos invitan a adentrarnos en la transición del habitus de ser estudiante al habitus de ser profesor, sentenciando que con la Formación Inicial Docente no es suficiente dicha transformación, pues este saber construido socialmente se transforma en el tiempo y en el campo laboral, requiere de madurez y del ejercicio profesional.

José Tejeda, construye un concepto de identidad docente que incluye una identidad profesional con otra laboral. Desde allí sea más conveniente hablar en plural de identidades docentes dada su heterogénea configuración.

El siguiente capítulo de Alberto Galaz, pone énfasis en la construcción interna de la identidad, más que la adquisición de modelos externos. Asimismo, invita a atender la identidad docente como elemento clave para la concreción de las políticas públicas en los contextos escolares lo cual no está siendo considerado en las actuales reformas neoliberales. Para ello invita a conformar comunidades profesionales de aprendizaje que permitan el despliegue y co-construcción de identidades.

Por su parte, José Gairín invita a pensar el proceso de construcción de identidad docente como una acción colectiva y colaborativa, por ello las comunidades educativas entendidas como redes de creación y gestión del conocimiento coadyuvan a construir identidad a través de procesos de reflexión colectiva.

El capítulo de Zabalza, Zabalza y de Côrte exponen un tema controversial dedicado a la identidad del profesorado universitario, por lo que significan las múltiples funciones de investigación y docencia que implica su labor académica, así como el cambio que en los últimos años han sufrido las universidades en torno a su sentido y función social, así como su estructura interna y financiación.

El noveno capítulo escrito por Arias, Baelo y Cañon, está centrado en profesores de primaria y se exhibe como una suerte de trayectoria profesional marcada por fases desde su formación inicial hasta su jubilación construyendo su identidad a través de sus experiencias vidas en el ejercicio de la su labor, por tanto, en permanente evolución. 
El texto de Marcel y Cenzano-Vilchez, invita a leer sobre la destrucción de la identidad del profesor de secundaria, critica aguda a partir de un reportaje de la televisión francesa que muestra los fácil que es conseguir un puesto de profesor a quien no tiene los antecedentes mínimos. Con este ejemplo reflexionan sobre qué es ser profesor, su rol social poniendo en cuestión la controversial relación entre profesión o vocación y entre "civilización" y "barbarie".

El capítulo de Margarita Pino aborda un tema complicado sobre el bienestar docente, abordado desde la legislación y la salud ocupacional, haciéndose propuestas para atender ante la aparición de ciertas enfermedades.

El capítulo escrito por Danièle Périsset cierra el libro relatando cómo los planes de estudio entendidos como proyecto político y social configuran una identidad profesional en la formación de profesores. Para ello analiza el caso de la Alta Escuela Pedagógica de nivel Universitario de Valais en Suiza.

Por último, esta recensión no ha tendido pretensión de exhaustividad, pues lo que busca es invitar a leer el libro, luego de ello cada lector sacará sus propias conclusiones y de seguro hallará otros sentidos y elementos destacados en cada uno de los capítulos. 